\title{
Durian Floral Differentiation and Flowering Habit
}

\author{
Chitose Honsho, Keizo Yonemori'1, Akira Sugiura \\ Graduate School of Agriculture, Kyoto University, Sakyo-ku, Kyoto 606-8502, Japan \\ Songpol Somsri \\ Horticulture Research Institute, Department of Agriculture, Chatuchak, Bangkok 10900, Thailand
}

\author{
Suranant Subhadrabandhu ${ }^{2}$ \\ Department of Horticulture, Faculty of Agriculture, Kasetsart University, Bangkok 10900, Thailand
}

AdDITIONAL INDEX wORDs. Durio zibethinus, floral differentiation, heterostyly, pollination, SEM observation

\begin{abstract}
Flower bud differentiation and the flowering habit of durian (Durio zibethinus Murray) 'Mon Thong' from budbreak to anthesis were investigated at the Chantaburi Horticultural Research Center in Thailand. Clusters of flower buds appeared at the end of November on primary or secondary scaffold branches near where a flower cluster occurred the previous year. Anatomical observations revealed that the development of floral organs was acropetal; the five fused epicalyx forming a large, elongated envelope enclosing the sepals, petals, stamen and fused multi-carpellate pistil. Floral organ development was completed in early January. The mature flower bud more than doubled in size one day before anthesis, with anthesis starting around $1600 \mathrm{HR}$ and ending $\approx 1900 \mathrm{HR}$. The anthers did not dehisce until the completion of flowering. This change induced heterostyly in this cultivar, which promoted out-crossing by reducing the possibility of self-pollination. Aromatic nectar that attracted insects to the flower was secreted during anthesis. This is the first report to have clarified the overall flowering process in durian and provides the basic information for elucidating reproductive biology of durian in future research.
\end{abstract}

Durian (Durio zibethinus Murray), one of the most important fruits in Southeast Asia, is one of 27 species in the family Bombacaceae (Kostermans, 1958). Within the genus Durio, only durian is widely distributed and cultivated; a few species bear edible fruit (Soegeng-Reksodihardjo, 1962). The durian is a native of Malaysia and Borneo, but its distribution has spread from Sri Lanka to New Guinea and from Hawaii to northern Australia (Yaccob and Subhadrabandhu, 1995). Although the fruit has a strong odor, its flavor has gained wide acceptance in all parts of the world. In recent years, Thailand has been the major producer of durian, with yields increasing from 426,245 metric tons in 1987 to 780,393 metric tons in 1994 (Subhadrabandhu and Ketsa, 2001).

Durian has an unusual reproductive biology, being a cauliflorous plant (Davis and Bhattacharya, 1974) with most flower clusters appearing on primary or secondary scaffold branches. The clusters consist of 5 to 30 flowers that are hermaphroditic, nocturnal, and strongly odorous (Davis and Bhattacharya, 1974). Valmayor et al. (1965) observed that all fully developed buds in the Philippines opened $\approx 1700 \mathrm{HR}$ and all flower organs except the pistil abscised by $2300 \mathrm{HR}$. Most flowers abscised after anthesis, resulting in low fruit set.

There are several reports that pollination of durian flower is mediated by bats at night (Baker, 1969; Soepadmo and Eow, 1977; Subhadrabandhu et al., 1991), though flowers are visited by insects during anthesis. The species is thought to be self-incompatible (Somsri, 1987; Subhadrabandhu et al., 1991; Valmayor et al., 1965), although Subhadrabandhu et al. (1991) stated that orchards planted with a single cultivar in Thailand show no signs of reduced fruit set. Basic information on floral differentiation and anthesis is lacking in durian. Therefore, this study focused on the

Received for publication 30 Dec. 2002. Accepted for publication 5 Aug. 2003. The authors would like to thank Sookwat Chandraparnik, the director of Chantaburi Horticultural Research Center, for providing plant materials, and Kay Ryugo for critical review of the manuscript.

1To whom reprint requests should be addressed; e-mail keizo@kais.kyoto-u.ac.jp. ${ }^{2}$ Deceased (16 July 2003). development of floral organs from bud emergence to anthesis using the scanning electron microscope (SEM) and stereomicroscope, and investigated the flowering process of durian flower as the first step for elucidating their reproductive biology.

\section{Materials and Methods}

Plant material AND Sampling. Observations were made in the durian production main area at the Chantaburi Horticultural Research Center (CHRC) in eastern Thailand (Subhadrabandhu, 1993, 1995). The leading Thai cultivar Mon Thong was used. Numerous flower clusters each bearing several buds $(\approx 3 \mathrm{~mm}$ in diameter) were tagged on 30 Nov. 2000. Ten or more buds were sampled at random from the tagged clusters on 2, 7, 14, 22, and 28 Dec. 2000 and 4 Jan. 2001. Buds less than $3 \mathrm{~mm}$ in diameter were also collected from nontagged clusters on 2 Dec. for SEM observations. Since floral initiation of durian is not strictly synchronous, buds of several stages of floral development were obtainable on the same day. Bud diameter and length were measured with a vernier caliper, and all buds (10) were immediately fixed in FAA solution according to Johansen (1940) and prepared for microscopic observations.

OBSERVATIONS ON THE EARLY STAGES OF FLORAL DIFFERENTIATION. Buds sampled on 2 Dec. were arranged by size, which consisted of the samples $<3 \mathrm{~mm}$ in diameter without tags and those $>3 \mathrm{~mm}$ in diameter with tags. Scanning electron microscopy (SEM) was used for observation of floral organs. Some were partially dissected by removing the epicalyx, calyx and corolla to disclose inner organs before dehydration in an ethanol series of $30 \%, 50 \%, 70 \%$, and $90 \%$ followed by $100 \%$ ethanol. Ethanol in the samples was replaced by amylacetate and dried by a critical-point dryer (HCP-2; Hitachi Co. Ltd., Japan) using liquid $\mathrm{CO}_{2}$. Dried samples were coated with gold in an ion sputter (E-101; Hitachi Nakaseiki Co. Ltd., Japan), and evaluated with a scanning electron microscope (S-2150; Hitachi).

OBSERVATIONS ON THE LATE STAGES OF FLORAL DIFFERENTIATION. Developing buds collected from 2 Dec. to 4 Jan. were cut 
Fig. 1. Parts of a dissected durian flower. Bar $=5 \mathrm{~cm}$. $\mathrm{ST}=$ stigma $; \mathrm{SY}=$ style $; \mathrm{OV}=$ ovary $; \mathrm{PD}=$ pedicel; $\mathrm{AT}=$ anther; $\mathrm{FL}=$ filament. Whole flower is shown in upper left corner.

longitudinally to expose the epicalyx, calyx, petals, stamens and pistils, and photographed with a stereomicroscope (SZX12; Olympus Optical Co. Ltd., Tokyo, Japan). In addition, mature buds on the day before anthesis and on the day of anthesis were collected and the length of their stamens and pistils were measured.

TIME-COURSE OF ANTHESIS. To record the process of flower opening, those undergoing anthesis were photographed with a digital camera on 30 Dec. from 1600 to $1800 \mathrm{HR}$ at 15-min intervals, at $1900 \mathrm{HR}$, and at 1200 HR the next day.

\section{Results and Discussion}

StruCtURe OF DURIAN Flower. Durian flower buds were cauliflorous and appeared
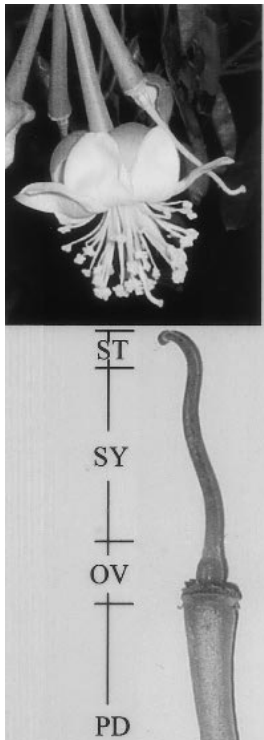

$\mathrm{PD}$

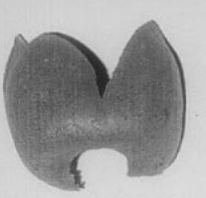

Epicalyx

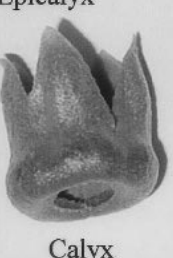

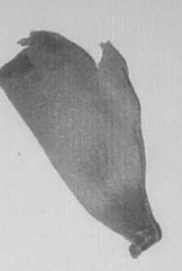

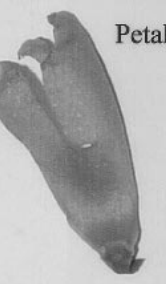

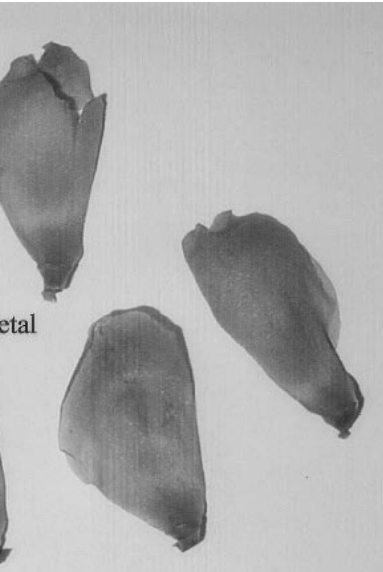

istil

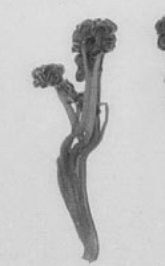

in clusters. One cluster, a cymose inflorescence, consisted of mostly 20 to 30 flower buds. Two or three pedicels diverged at the node of peduncle. Flower clusters appeared from November to December on primary or secondary scaffold branches often at vestigial positions where a flower cluster had appeared previously. Clusters hung from the branch with their flowers dangling downward.

At bloom (the beginning of January in $\mathrm{CHRC}$ ), width of durian flowers averaged 5 $\mathrm{cm}$ and consisted of the epicalyx, calyx, five petals, five bundles of stamens and a pistil (Fig. 1). The epicalyx formed an envelope that covered the other organs before anthesis. The calyx was crown-like, having five sepals fused at their bases. Petals were creamy yellow and attractive. Stamen bundles consisted of many fused, twisted, branched filaments having numerous anthers. Each filament within bundles fused at its base. The pistil consisted of stigma, style of $\approx 5 \mathrm{~cm}$ length and ovoid ovary.

EARLY DEVELOPMENT OF FLORAL ORGANS. At budbreak (the end of November), buds appeared as small protuberances with scales enclosing numerous floral primordia (Fig. 2A). As the bud enlarged, the scales and epicalyces expanded revealing five calyx primordia inside the protuberance (Fig. 2B). Five petals, five

Fig. 2. Scanning electron micrographs showing floral differentiation in Durio zibethinus. (A) Intact flower bud as a protuberance covered with scales arising from a trunk or branch, (B) five calyces differentiating to form a dome, $(\mathbf{C})$ differentiation of five petals revealed when the calyx primordia were removed, (D) stamen and pistil primordia, (E) differentiation of anthers and five fused carpels, and (F) ovary with five completely fused carpels. Magnification and scale bar are shown at the bottom of each picture. $\mathrm{CL}=$ calyx; $\mathrm{PT}=$ petal; $\mathrm{EC}=$ epicalyx; $\mathrm{ST}=$ stamen $; \mathrm{CP}=$ carpel $; \mathrm{SC}=$ scale .
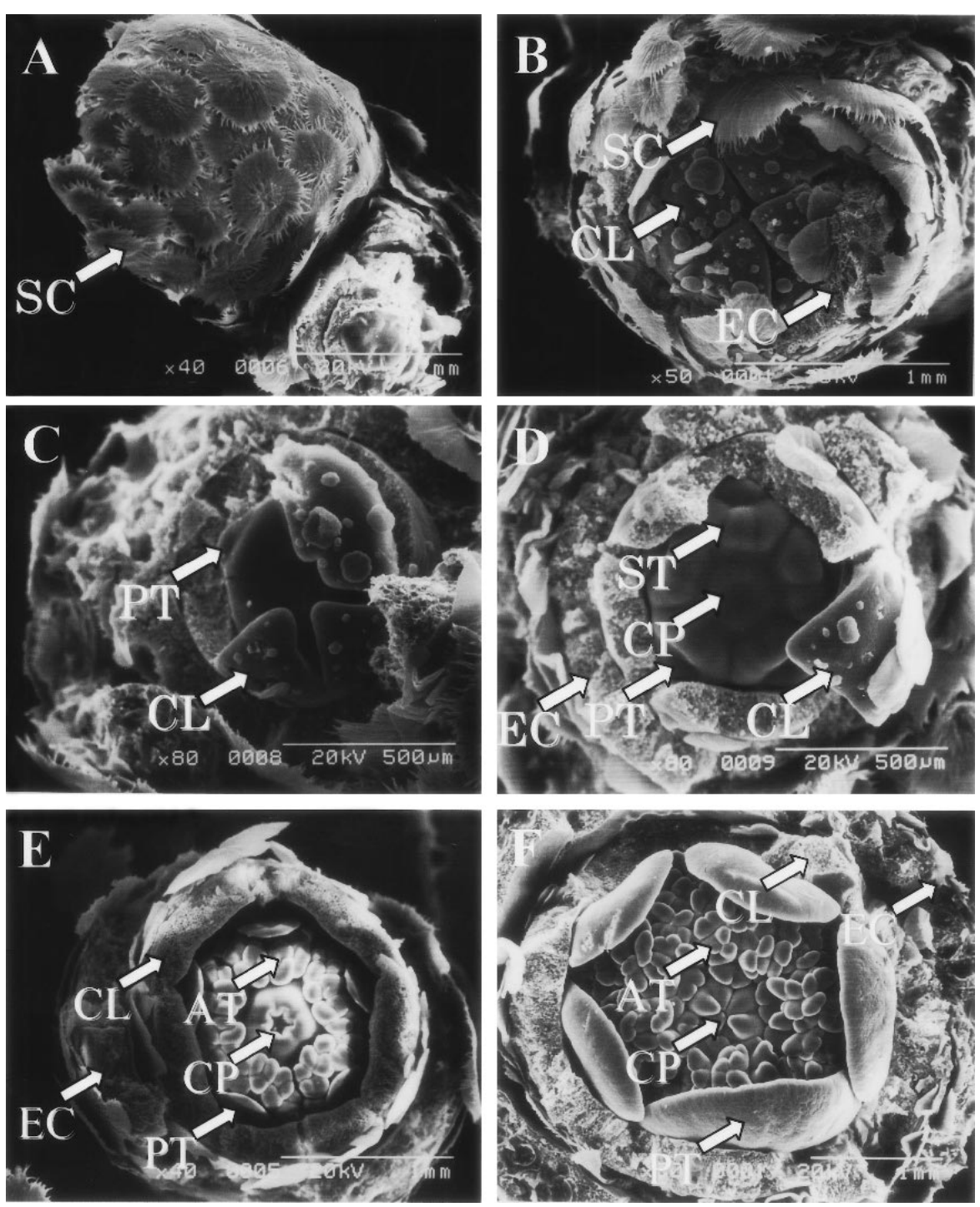

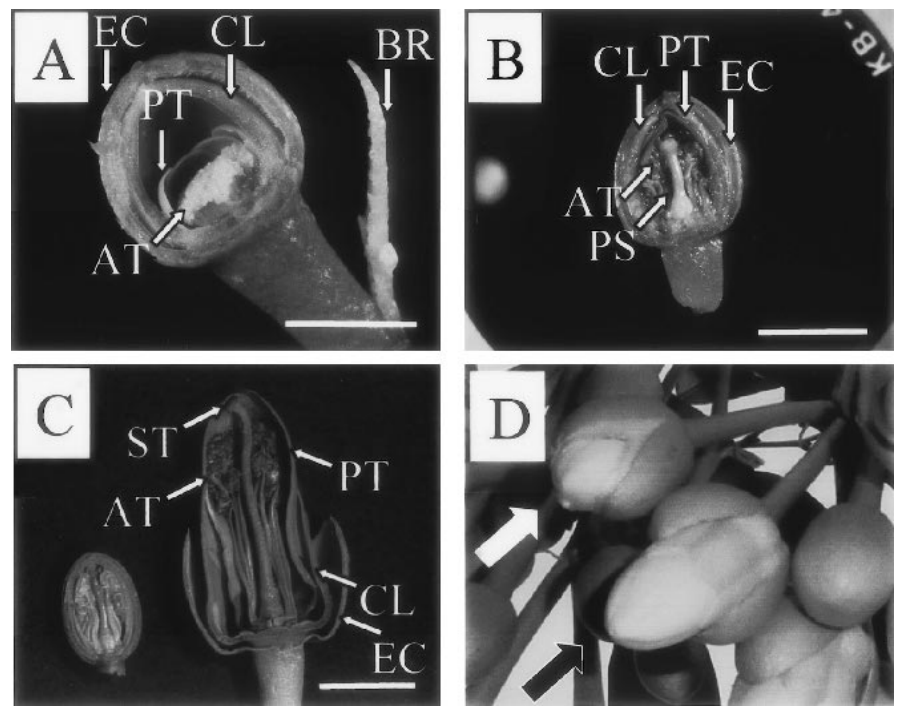

Fig. 3. Developmental sequences of floral differentiation and development. (A) Bud on 7 Dec., (B) Bud on 14 Dec., (C) Mature bud the day before anthesis (left), and a bud just before anthesis (right), (D) Flower buds the day before and at anthesis; white arrow indicates the bud the day before anthesis and black arrow points to buds that will open that afternoon. Bar $=0.5 \mathrm{~cm}, 1 \mathrm{~cm}, 2 \mathrm{~cm}$ in $\mathrm{A}, \mathrm{B}$ and $\mathrm{C}$, respectively. $\mathrm{EC}=$ epicalyx $\mathrm{CL}=$ calyx; $\mathrm{PT}=$ petal; $\mathrm{BR}=$ bract; $\mathrm{PS}=$ pistil; $\mathrm{AT}=$ anther; $\mathrm{ST}=$ stigma.

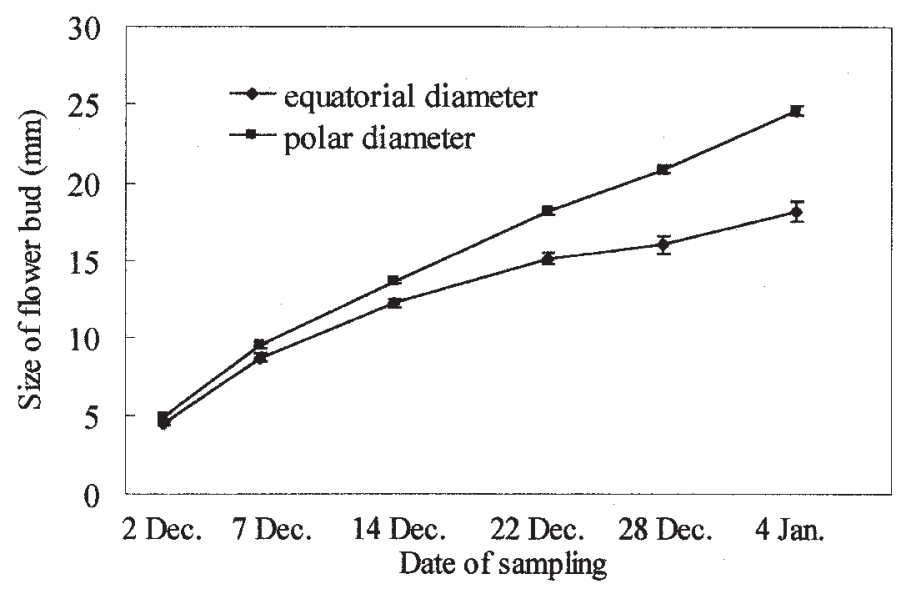

Fig. 4. Seasonal changes in equatorial and polar diameter of flower bud from December to January. Vertical bars indicate standard error $(n=10)$.

stamens and five carpels differentiated acropetally in succession (Fig. 2C and D). The stamen primordium developed numerous filaments with anthers that were fused at their bases to form bundles of stamen (Fig. 2E). When the diameter of bud was greater than $3 \mathrm{~mm}$, the five carpels fused and formed a stigma (Fig. 2F).

The factors that induce floral initiation in durian are yet unknown (Subhadrabandhu et al., 1991). Lim and Luders (1998) surmised that several nights below $15^{\circ} \mathrm{C}$ in Australia could cause the appearance of floral protuberances on branches 1 to 2 weeks later, followed by flowering after 4 to 6 weeks. In Chantaburi, however, temperature is not a factor for floral induction because it is relatively constant and the monthly average minimum hovers over $20^{\circ} \mathrm{C}$ throughout the year. Water stress or relative humidity could be factors as the rainy season in Chantaburi ends in September and the dry period lasts until May. The start of the dry period in Chantaburi coincides with the time of floral initiation. Floral induction by water stress has been reported in mango, carambola (Nakasone and Paull, 1998a, 1998b) and lychee (Menzel, 1983).
Water stress may be essential for tropical and subtropical fruit to induce floral initiation.

LATE DEVELOPMENT OF FLORAL ORGANS. Between 2 and 7 Dec., the epicalyx became cup-shaped and the calyx and petals were visible within it (Fig. 3A). Filaments of the stamen and pistil began to elongate, such that on $14 \mathrm{Dec}$., the stigma, pistil and ovary were fully differentiated (Fig. 3B). Buds continued enlargement until 4 Jan. (Fig. 3C) when they were completely mature, just prior to anthesis. No significant morphological change occurred during this period. The size of flower buds averaged $24.6 \mathrm{~mm}$ in length and $18.2 \mathrm{~mm}$ in width just before anthesis on 4 Jan. (Fig. 4). Equatorial and polar diameter increased proportionately from 2 to 7 Dec., but the polar diameter increased more rapidly than equatorial diameter, such that the bud shape changed from a sphere to an ellipsoid structure. Flower buds were fully mature at the beginning of January. On the day before anthesis, the epicalyx split to expose the calyx (Fig. 3D). By the following morning, the stamens and pistil doubled in size (Fig. 3C; Table 1). The pistil length $(1.84 \mathrm{~cm})$ was almost equal to that of the stamen $(1.81 \mathrm{~cm})$ on the day before anthesis, whereas pistil length $(4.40 \mathrm{~cm})$ was greater than stamen length $(3.44 \mathrm{~cm})$ just before anthesis. Thus, this change induced heterostyly in this cultivar. The relationship between heterostyly and self-incompatibility has not been determined. However, pollination of durian requires pollen vectors, not wind (Valmayor et al., 1965). Therefore, heterostyly creates a spatial gap between the anther and stigma that is enough to hinder self-pollination, even if the degree of heterostyly is less than other heterostylous plants such as carambola (Chin and Phoon, 1982; Moncur, 1988).

Time-COURSE OF ANTHESIS. Bloom lasted throughout January. The time-course of flower opening shows that flowers started to open around $1600 \mathrm{HR}$ and completed opening around $1900 \mathrm{HR}$. Anther dehiscence occurred toward the end of anthesis. All floral organs except for the gynoecium abscised by the next morning. During flower opening, insects were attracted by the aromatic nectar secreted from the nectary at the base of each sepal. Bat pollination in durian has been previously reported (Baker, 1969; Soepadmo and Eow, 1977; Subhadrabandhu et al., 1991). Several features of the durian flower (e.g., whitish or creamy petal color, large flowers, large anthers, cauliflory) are amenable to bat pollination (van der Pijl, 1961; Faegri and van der Pijl, 1971). Our data on floral structure supports this supposition, but bats were not observed during the experiment. Although insects visited the flowers, their role as pollinating vectors is unknown. The effective pollination period and the exact time of anther dehiscence should be determined to elucidate the possibility of entomophily, and those results will provide a better understanding of the cause of low fruit set in durian.

\section{Conclusion}

In the present report, we confirmed the structure of durian flowers and clarified early processes of floral organ development by SEM observations, as well as late processes of floral

Table 1. Stamen and pistil length of the flower bud at the day before and just before anthesis.

\begin{tabular}{lcc}
\hline Flower & \multicolumn{2}{c}{ Length $(\mathrm{cm})$} \\
\cline { 2 - 3 } part & Day before anthesis & Just before anthesis \\
\hline Stamen & $1.81 \pm 0.03^{z}$ & $3.44 \pm 0.09$ \\
Pistil & $1.84 \pm 0.02$ & $4.40 \pm 0.06$ \\
\hline
\end{tabular}

${ }^{z}$ Mean of 20 stamens or pistils \pm SE. 
development by stereomicroscopic observations. According to our observations, the development of floral parts within the bud required more than a month. In addition, our observations revealed a dramatic increase in flower bud size the night before anthesis, which induced heterostyly. We propose that heterostyly is associated with avoidance of self-pollination in durian flower. Further investigation into the possibility of insect pollination in durian would be necessary for understanding the reproductive biology in durian.

\section{Literature Cited}

Baker, H.G. 1969. Two cases of bat pollination in central America. Revista Biol. Trop. 17(2):187-197.

Chin, H.F. and A.C.G. Phoon. 1982. A scanning electron microscope study of flower of carambola, durian and rambutan. Pertanika 5(2): 234-239.

Davis, T.A. and C. Bhattacharya. 1974. Some morphological observations in Durio zibethinus Murr. (Bombacaceae). J. Ind. Bot. Soc. 53: $48-58$.

Faegri, K. and L. van der Pijl. 1971. Pollination by bats. Chiropterophily, p. 151-158. In: K. Faegri and L. van der Pijl (eds.). The principles of pollination ecology (2nd rev. ed.). Pergamon Press Ltd., Headington Hill Hall, Oxford.

Johansen, D.A. 1940. Plant microtechnique. McGraw-Hill, New York. Kostermans, A.J.G.H. 1958. The genus Durio Adans. (Bombac.). Reinwardtia 4:357-460.

Lim, T.K. and L. Luders. 1998. Durian flowering, pollination and incompatibility studies. Ann. Appl. Biol. 132:151-165.

Menzel, C.M. 1983. The control of floral initiation in lychee: A review. Scientia Hort. 21:201-215.

Moncur, M.W. 1988. Durio zibethinus Murr., p. 30-33. In: M.W. Moncur (ed.). Floral development of tropical and subtropical fruit and nut species. CSIRO, Melbourne, Australia.
Nakasone, H.Y. and R.E. Paull. 1998a. Mango, p. 208-238. In: H.Y. Nakasone and R.E. Paull (eds.). Tropical fruits. CAB Intl., Wallingford. Nakasone, H.Y. and R.E. Paull. 1998b. Carambola, p. 132-148. In: H.Y. Nakasone and R.E. Paull (eds.). Tropical fruits. CAB Intl., Wallingford.

Soegeng-Reksodihardjo, W. 1962. The species of Durio with edible fruits. Economic Bot. 16:270-282.

Soepadmo, E. and B.K. Eow. 1977. The reproductive biology of Durio zibethinus Murr. Garden's Bul. 29:25-33.

Somsri, S. 1987. Studies on hand pollination of durian (Durio zibethinus L.) cvs. Chanee and Kan Yao by certain pollinizers (in Thai with English abstract). MS thesis. Kasetsart Univ., Bangkok, Thailand.

Subhadrabandhu, S., J.M.P. Schneemann, and E.W.M. Verheij. 1991. Durio zibethinus Murray, p. 157-161. In: E.W.M. Verheij and R.E. Coronel (eds.). PROSEA: Plant resources of South-East Asia. vol. 2. Edible fruits and nuts. Pudoc, Wageningen.

Subhadrabandhu, S. 1993. Current status and future strategies in durian and mangosteen research in Thailand, p. 129-136. In: Prosiding Simposium Buah-Buahan Kebangsaan Ketiga 1991. MARDI, Kuala Lumpur, Malaysia.

Subhadrabandhu, S. 1995. Commercial production of tropical fruits with emphasis on durian, mangosteen, rambutan and longkong, $\mathrm{p}$. 151-162. In: W.M.W. Othman, K. Sijam, S.H. Ahmad, and N.M.N. Hassen (eds.). Commercial production of fruits, vegetables and flowers. Univ. Pertanian Malaysia Publ.

Subhadrabandhu, S. and S. Ketsa. 2001. Area of production and economic importance, p. 11-24. In: S. Subhadrabandhu and S. Ketsa (eds.). Durian-King of tropical fruit. CABI Publ., Wellington, N.Z.

Valmayor, R.V., R.E. Coronel, and D.A. Ramirez. 1965. Studies on the floral biology, fruit set and fruit development in durian. Philippine Agr. 48:355-366.

van der Pijl, L. 1961. Ecological aspects of flower evolution II. Zoophilous flower classes. Evolution 15:44-59.

Yaacob, O. and S. Subhadrabandhu. 1995. Durian (Durio zibethinus Murr.), p. 90-108. In: O. Yaacob and S. Subhadrabandhu (eds.). Pro- 